\title{
Combining the flexibility from shared energy storage systems and DLC-based demand response of HVAC units for distribution system operation enhancement
}

\author{
Citation for published version (APA): \\ Tascikaraoglu, A., Paterakis, N. G., Erdinc, O., \& Catalao, J. P. S. (2019). Combining the flexibility from shared \\ energy storage systems and DLC-based demand response of HVAC units for distribution system operation \\ enhancement. IEEE Transactions on Sustainable Energy, 10(1), 137-148. [8340882]. \\ https://doi.org/10.1109/TSTE.2018.2828337
}

\section{Document license: \\ TAVERNE}

DOI:

10.1109/TSTE.2018.2828337

Document status and date:

Published: 01/01/2019

\section{Document Version:}

Publisher's PDF, also known as Version of Record (includes final page, issue and volume numbers)

\section{Please check the document version of this publication:}

- A submitted manuscript is the version of the article upon submission and before peer-review. There can be important differences between the submitted version and the official published version of record. People interested in the research are advised to contact the author for the final version of the publication, or visit the $\mathrm{DOI}$ to the publisher's website.

- The final author version and the galley proof are versions of the publication after peer review.

- The final published version features the final layout of the paper including the volume, issue and page numbers.

Link to publication

\footnotetext{
General rights

- You may freely distribute the URL identifying the publication in the public portal. follow below link for the End User Agreement:

www.tue.nl/taverne

\section{Take down policy}

If you believe that this document breaches copyright please contact us at:

openaccess@tue.nl

providing details and we will investigate your claim.
}

Copyright and moral rights for the publications made accessible in the public portal are retained by the authors and/or other copyright owners and it is a condition of accessing publications that users recognise and abide by the legal requirements associated with these rights.

- Users may download and print one copy of any publication from the public portal for the purpose of private study or research.

- You may not further distribute the material or use it for any profit-making activity or commercial gain

If the publication is distributed under the terms of Article $25 \mathrm{fa}$ of the Dutch Copyright Act, indicated by the "Taverne" license above, please 


\title{
Combining the Flexibility From Shared Energy Storage Systems and DLC-Based Demand Response of HVAC Units for Distribution System Operation Enhancement
}

\author{
Akın Taşcıkaraoğlu ${ }^{\circledR}$, Member, IEEE, Nikolaos G. Paterakis ${ }^{\circledR}$, Member, IEEE, Ozan Erdinç, Senior Member, IEEE, \\ and João P. S. Catalão ${ }^{\circledR}$, Senior Member, IEEE
}

\begin{abstract}
In this study, a direct load control strategy for procuring flexibility from residential heating, ventilation, and air conditioning (HVAC) units and the optimal management of shared energy storage systems connected at different buses of a distribution system is proposed, as a new contribution with respect to earlier studies, aiming to minimize the energy demand during DR event periods. Moreover, an additional objective related to the minimization of the end-users' discomfort induced by the interruption of the HVAC units is considered, leading to the formulation of a bi-level optimization problem based on a second-order conic programming representation of the $\mathrm{AC}$ power flow equations. The effectiveness of the proposed methodology is demonstrated by performing simulations on a test system and comparisons with other approaches.
\end{abstract}

Index Terms-Bi-level optimization, demand response, direct load control, HVAC, shared energy storage.

Manuscript received September 17, 2017; revised January 7, 2018 and March 10, 2018; accepted April 16, 2018. Date of publication April 18, 2018; date of current version December 14, 2018. This work was supported mainly by the Scientific and Technological Research Council of Turkey (TUBITAK) under Project Grants 116E115 and 117E527; in part by the FEDER funds through COMPETE 2020; and in part by the Portuguese funds through Fundação para a Ciência e a Tecnologia, under Projects SAICT-PAC/0004/2015 - POCI-01-0145-FEDER016434, POCI-01-0145-FEDER-006961, UID/EEA/50014/2013, UID/CEC/ 50021/2013, UID/EMS/00151/2013, SFRH/BPD/103744/2014, and 02/SAICT 12017 - POCI-01-0145-FEDER-029803. Also, the research leading to these results was supported by the EU Seventh Framework Programme FP7/2007-2013 under Grant 309048. Paper no. TSTE-00861-2017. (Corresponding author: João P. S. Catalão.)

A. Taşc1karaoğlu is with the Department of Electrical and Electronics Engineering, Mugla Sitki Kocman University, Mugla 48000, Turkey (e-mail: akintascikaraoglu@mu.edu.tr).

N. G. Paterakis is with the Department of Electrical Engineering, Eindhoven University of Technology, Eindhoven 5612 AJ, The Netherlands (e-mail: n.paterakis@tue.nl).

O. Erdinç is with the Department of Electrical Engineering, Yildiz Technical University, Istanbul 34349, Turkey (e-mail: oerdinc@yildiz.edu.tr).

J. P. S. Catalão is with INESC TEC and the Faculty of Engineering of the University of Porto, Porto 4200-465, Portugal, also with C-MAST, University of Beira Interior, Covilhã 6201-001, Portugal, and also with INESC-ID, Instituto Superior Técnico, University of Lisbon, Lisbon 1049-001, Portugal (e-mail: catalao@ubi.pt).

Color versions of one or more of the figures in this paper are available online at http://ieeexplore.ieee.org.

Digital Object Identifier 10.1109/TSTE.2018.2828337

\section{INTRODUCTION}

\section{A. Motivation}

Smart grid applications have been attracting increasing interest, particularly in the light of the ever increasing electricity demand and the subsequent concerns regarding the efficient operation of power systems. In addition to their impact on augmenting and diversifying the energy production mix, especially by exploiting renewable energy sources, such environments enable the active participation of consumers through demand response (DR) and the incorporation of energy storage systems (ESS) into the grid. The role of such technologies is primordial in making better use of the available infrastructure by alleviating issues related to the limited operational flexibility of the existing structures [1], [2].

Recently the amount of the electrical energy consumed by residential end-users has substantially increased, reaching almost $40 \%$ of the global electricity demand [3]. As a result, many studies have concentrated on applications such as residential DR programs and the integration of small-scale storage systems, aiming to exploit this significant potential for energy and cost savings [4]-[6].

As regards DR programs, the relevant literature has mostly focused on examining the operational benefits of engaging commercial and industrial end-users mainly due to the relatively higher portion of demand that these consumer types represent and the fact that their power profiles are more predictable. However, the increasing residential consumption and the widespread adoption of smart meters have motivated studies about DR applications at the residential level, since successfully engaging residential end-users may enable a source of system services. In fact, load serving entities (LSE) have been effectively procuring reductions of residential consumption during high power demand periods through direct load control (DLC) and pricebased programs, with the former being generally considered a more successful approach [7], [8].

The widespread adoption of renewable energy sources and the potential for initiating residential DR programs has considerably increased the necessity of integrating ESS. These systems can contribute to the exploitation of renewable energy generation 
by storing the excess energy and to the effectiveness of a DR program by using the stored energy when needed, particularly during energy-intensive periods. The use of battery-based ESS in residential premises has been extensively studied in the literature. However, the considerable investment costs and space limitations within the houses have limited the use of behindthe-meter storage systems. In order to overcome this challenge, the use of a relatively higher-capacity battery bank that is located in a dedicated area and is accessible by a cluster of houses represents a promising alternative. Using a high-capacity storage system that is shared between several houses in a wider area instead of using one battery for each house bears the advantage of reducing the investment, maintenance, operational and replacement costs per end-user. This solution is generally referred to as a shared ESS, a common storage or a community storage in the literature. Among them, the term shared ESS is more widely-used for DR-related applications while the two others are generally preferred to define the storage units employed during abnormal network conditions, e.g., during power outages [9]-[13].

\section{B. Literature Overview}

In the relevant literature, various studies have considered grid-connected, behind-the-meter batteries with the objective of either providing the energy required for residential selfconsumption or of raising revenue by selling excess energy back to the grid [14]-[17].

Several researchers extended this concept by considering multiple houses equipped with batteries and by investigating both individual and collective (neighborhood level) benefits. Ye et al. [18] considered a neighborhood area network (NAN) and photovoltaic (PV) panels supported by batteries and proposed an optimization problem formulation to achieve cost minimization.

With the same objective, Singla et al. [19] examined the optimum battery size for a neighborhood of 100 homes. Guo et al. [20] presented a Lyapunov-based energy management algorithm for the minimization of the total energy costs in a neighborhood which may include renewable generation and ESS. The reduction of the energy costs in a residential neighborhood using batteries was studied in [21].

Bozchalui et al. [22] presented optimization models for residential energy hubs aiming to control residential appliances, PV generation and batteries, with the purpose of reducing energy consumption, considering also end-users' preferences. An approach for the coordination of multiple battery ESS was introduced in [23] for controlling voltage variations caused by PV systems.

Compared to the individual storage units, the shared ESS generally provide higher cost savings and benefits for both the consumers and aggregators; however, in order to fully make use of these structures, a dedicated energy management algorithm must be developed considering the complex interactions between each consumer and the shared ESS, between each consumer and the grid, and also between the grid and the shared ESS.

For instance, in [24] an approach for the control of the ESS of individual consumers was proposed, while the cost savings of this approach were then examined for a scenario with shared
ESS. Since the proposed method was tailored to individual consumers, insignificant differences between the two scenarios were reported.

On the contrary, Rahbar et al. [9] studied the optimal energy management for multiple end-users with renewable energy integration and a shared ESS, and presented considerable results showing the benefits of introducing a shared ESS. Mediwaththe et al. [25] introduced an energy trading method based on the load management of a NAN including a shared ESS device and consumers with PV panels, in which excess energy is sold to the grid and/or used for charging the ESS according to the decisions of the end-users.

However, this study focused on the financial benefits for individual consumers without considering operational aspects of the grid. Aiming at minimizing the aggregated electricity costs without dealing with energy reduction, a distributed optimization method was presented in [10] for a network of residential consumers. An aggregator was assumed to manage the interactions between the end-users and the grid, as well as a shared ESS, taking into account fairness concerns related to its use.

In a smart community including residential units and a battery, the benefits of distributed energy resources were evaluated in [26] without considering the problem from the perspective of the end-users. Good et al. [27] proposed a two-stage stochastic model for DR applications of ESS units while also taking the residential end-user's discomfort into account; however, the authors considered only thermal storage units. Without considering the end-users' comfort, the optimal allocation of shared ESS in a residential community was studied in [11], optimal management and sizing of ESS for improving DG hosting ability of the grid were assessed in [28], and a method based on switching droop control was presented in [29] for the coordinated operation of renewable energy sources and ESS.

Lastly, a DR management approach for a microgrid consisting of renewable energy sources and energy storage units was presented in [12] considering also the optimization of thermal comfort; however, in this study the storage units were used only for storing excessive renewable energy.

Apart from the studies that focused on the use of shared ESS units, the role of aggregators in distribution systems and wholesale electricity markets has been the topic of several studies.

Among them, Yang et al. [30] proposed a robust optimal bidding strategy for load aggregators in the electricity markets also considering the conditional Value-at-Risk metric. Xu et al. [31] considered the risk-averse bidding strategy of demand-side aggregators (flexible load and distributed generation) in day-ahead markets taking into account the uncertainty in the generation of renewables, real-time prices, and electricity demand.

There are also recent studies dedicated to electric vehicle aggregators and their participation in electricity markets [32][34]. Gkatzikis et al. [35] considered the role of aggregators of flexible residential demand in DR markets. A review of these aspects can be found in [36].

The thermostatically controllable appliances (TCA) - such as Heating, Ventilation and Air Conditioning (HVAC) units, refrigerators, electric water heaters, etc.- based DLC has been also studied in the literature. The readers are addressed to a 
TABLE I

SETS \& INDICES

\begin{tabular}{ll}
\hline$B_{l}^{i j}$ & Set of lines where $i$ is the sending and $j$ is the receiving \\
$B_{h}^{i}$ & bus. \\
$e$ & Set of houses connected to bus $i$. \\
$h$ & Index of structural elements. \\
$i$ & Index of houses. \\
1 & Index of buses. \\
$t$ & Index of lines. \\
\hline
\end{tabular}

previous study of the authors [8] for a detailed literature survey on this topic.

\section{Content and Contributions}

This study considers multiple shared ESS, each connected at a different bus of the distribution system, together with a number of residential end-users who form a smart energy hub. A strategy aiming at controlling these dispersed energy hubs to optimally respond to load reduction requests is proposed. The required load reductions are primarily satisfied by controlling the energy consumption of residential end-users that are enrolled to a DLCbased DR program. Specifically, HVAC units are employed due to their relatively high power capacity and the fact that the thermal inertia in building structures allows for the interruption of their service without directly affecting the end-users' comfort level [37].

In order to provide more flexibility in meeting the desired load reductions, in particular during critical demand periods, the energy that is stored in shared ESS is also used. Besides, since the smart energy hubs are located in a wide area, several power system constraints such as power losses are also taken into account in the optimum system operation through a second order conic programming formulation of the $\mathrm{AC}$ power flow equations.

The contribution of this study is twofold:

- The possibility of combining the flexibility from multiple shared ESS units and DLC-based DR of HVAC units is evaluated. To the best of the authors' knowledge this is a topic that has not been studied in the technical literature yet.

- A bi-level DLC-based DR optimization algorithm is developed, in which the upper-level problem aims to satisfy the operational targets of the Distribution System Operator (DSO), while the lower-level problem aims to minimize the end-users' discomfort in order to meet the requirements regarding the quality of the services offered by the LSE to the enrolled customers.

\section{Organization of the Paper}

The remainder of the paper is organized as follows: the proposed optimization model is presented in Section II. Then, the effectiveness of the proposed methodology is examined through case studies that are discussed in Section III. Finally, concluding remarks and directions for future studies are presented in Section IV. The sets, parameters and decision variables used in this study are alphabetically listed in Tables I-III.
TABLE II

PARAMETERS \& CONSTANTS

\begin{tabular}{|c|c|}
\hline$A_{e, h}$ & Area of structural element $e$ in house $h\left[\mathrm{~m}^{2}\right]$. \\
\hline$B_{l}$ & Susceptance of line $l[\mathrm{pu}]$. \\
\hline$c_{a}$ & Thermal capacity of air $\left[\mathrm{kJ} / \mathrm{kg} \cdot{ }^{\circ} \mathrm{C}\right]$ \\
\hline$C E_{i}^{S S}$ & Charging efficiency of the shared storage system at bus $i$. \\
\hline $\mathrm{COP}_{h}$ & Coefficient of performance of HVAC in house $h$. \\
\hline$D E_{i}^{S S}$ & Discharging efficiency of the shared storage system at bus $i$. \\
\hline$K_{h, t}$ & Rated power of the HVAC system in house $h[\mathrm{pu}]$. \\
\hline$l_{e, h}$ & Thickness of structural element $e$ in house $h[\mathrm{~m}]$ \\
\hline$L x_{h}$ & Length, width and height of house $h$, where $x=\{1,2,3\}[\mathrm{m}]$ \\
\hline$M_{h}$ & Mass of air in household $h[\mathrm{~kg}]$ \\
\hline$M_{i, l}^{F}$ & $\begin{array}{l}\text { The coefficient that is } 1 \text { if bus } i \text { is the receiving end of line } l \text {, } \\
-1 \text { if bus } i \text { is the sending end of line } l \text {, otherwise } 0 \text {. }\end{array}$ \\
\hline$M_{i, l}^{L}$ & $\begin{array}{l}\text { The coefficient that is } 1 \text { if bus } i \text { is the sending end of line } l \text {, } \\
\text { otherwise } 0 \text {. }\end{array}$ \\
\hline$M_{l, i}^{W}$ & $\begin{array}{l}\text { The coefficient for bus } i \text { and line } l \text { obtained from the } \\
\text { transpose of the matrix composed of } M_{i, l}^{F} \text { values. }\end{array}$ \\
\hline$N^{h}$ & Number of houses that are controlled. \\
\hline$P_{i, t}^{L, \text { other }}$ & Inelastic demand of bus $i$ in period $t[\mathrm{pu}]$ \\
\hline$Q_{i, t}^{L}$ & Reactive power demand of bus $i$ in period $t[\mathrm{pu}]$. \\
\hline$R_{h}^{e q}$ & Thermal resistance of household $h\left[\mathrm{~h} \cdot{ }^{\circ} \mathrm{C} / \mathrm{J}\right]$ \\
\hline$R_{i}^{S S S, c h}$ & $\begin{array}{l}\text { Charging rate limit of the shared storage system connected } \\
\text { to bus } i[\mathrm{pu}] \text {. }\end{array}$ \\
\hline$R_{i}^{S S, d i s}$ & $\begin{array}{l}\text { Discharging rate limit of the shared storage system } \\
\text { connected to bus } i[\mathrm{pu}] \text {. }\end{array}$ \\
\hline$R_{l}$ & Resistance of line $l[\mathrm{pu}]$ \\
\hline $\operatorname{SOE} E_{i}^{S S, i n i}$ & $\begin{array}{l}\text { Initial SOE of the shared storage system connected to bus } i \\
{[\mathrm{pu}] \text {. }}\end{array}$ \\
\hline$S O E_{i}^{S S, \max }$ & $\begin{array}{l}\text { Maximum SOE of the shared storage system connected to } \\
\text { bus } i[\mathrm{pu}] \text {. }\end{array}$ \\
\hline$S O E_{i}^{S S, \min }$ & $\begin{array}{l}\text { Minimum SOE of the shared storage system connected to } \\
\text { bus } i[\mathrm{pu}] \text {. }\end{array}$ \\
\hline$T_{h}^{1}$ & Initial indoor temperature of household $\mathrm{h}\left[{ }^{\circ} \mathrm{C}\right]$ \\
\hline$T_{t}^{a}$ & Ambient temperature in period $t\left[{ }^{\circ} \mathrm{C}\right]$ \\
\hline$T_{h, t}^{d e s}$ & $\begin{array}{l}\text { User-selected temperature set-point in house } h \text { in period } t \\
{\left[{ }^{\circ} \mathrm{C}\right] .}\end{array}$ \\
\hline$T_{h}^{D B}$ & $\begin{array}{l}\text { Dead-band around the temperature set-point for the HVAC } \\
\text { unit of house } h\left[^{\circ} \mathrm{C}\right] \text {. }\end{array}$ \\
\hline$t_{1}$ & Starting time of the DR event. \\
\hline & Ending time of the DR event. \\
\hline$V_{h}$ & Volume of house $h\left[\mathrm{~m}^{3}\right]$ \\
\hline$V_{\max }$ & Maximum allowed voltage level for buses [pu]. \\
\hline$V_{\min }$ & Minimum allowed voltage level for buses [pu]. \\
\hline$X_{l}$ & Reactance of line $l[\mathrm{pu}]$ \\
\hline$\beta_{h}$ & Roof angle of household $h$ [deg]. \\
\hline$\delta_{\text {air }}$ & Air density $\left[\mathrm{kg} / \mathrm{m}^{3}\right]$ \\
\hline$\Delta T$ & Time granularity $[\mathrm{h}]$. \\
\hline$\sigma_{e, h}$ & Thermal coefficient of element $e$ in household $h\left[\mathrm{~J} / \mathrm{h} \cdot \mathrm{m}^{\left.\cdot{ }^{\circ} \mathrm{C}\right]}\right.$. \\
\hline
\end{tabular}

\section{Methodology}

In the proposed system structure, it is assumed that a medium voltage (MV) bus is connected to a number of low voltage (LV) buses, through which energy is supplied to a number of houses offering HVAC flexibility, as well as several small- and mediumscale commercial consumers. Each LV bus is also assumed to have shared ESS unit connected at the LV side of the distribution transformer, as shown in Fig. 1.

The proposed methodology controls the operation of residential HVAC units and shared storage systems aiming to minimize energy supply from the point of view of the DSO. In addition to that, the regulation of the HVAC loads should be performed in such a way that the minimization of the discomfort of the end-users is guaranteed.

This is an important aspect from the perspective of a LSE since the willingness of the end-users to respond to an event is a decisive factor for the success of DR strategies, which in turn depends both on the discomfort caused due to the response to an event and the incentives that are offered. It 
TABLE III

DECISION VARIABLES

\begin{tabular}{|c|c|}
\hline$\overline{P_{h, t}^{A C}}$ & $\begin{array}{l}\text { Actual HVAC unit power consumption of house } h \text { in period } \\
t \text { [pu]. }\end{array}$ \\
\hline$P_{i, t}^{G}$ & Power available at bus $i$ in period $t[\mathrm{pu}]$ \\
\hline$P_{i, t}^{L}$ & Total load of bus $i$ in period $t[\mathrm{pu}]$ \\
\hline$P_{i, t}^{S}$ & Local transformer supply at bus $i$ in period $t[\mathrm{pu}]$ \\
\hline$P_{i, t}^{S S, c h}$ & $\begin{array}{l}\text { Charging power of the shared storage system connected to } \\
\text { bus } i \text { in period } t[\mathrm{pu}] \text {. }\end{array}$ \\
\hline$P_{i, t}^{S S, d i s}$ & $\begin{array}{l}\text { Discharging power of the shared storage system connected } \\
\text { to bus } i \text { in period } t[\mathrm{pu}] \text {. }\end{array}$ \\
\hline$P_{l, t}^{l o s s}$ & Active power loss of line $l$ in period $t[\mathrm{pu}]$ \\
\hline$\hat{P}_{l, t}^{\text {ioss }}$ & $\begin{array}{l}\text { Model variable to represent the active power loss of line } l \text { in } \\
\text { period } t[\mathrm{pu}] \text {. }\end{array}$ \\
\hline$P_{l, t}^{r}$ & Active power flow at receiving end of line $l$ in period $t[\mathrm{pu}]$. \\
\hline$Q_{l, t}^{\text {iloss }}$ & Reactive power loss of line $l$ in period $t[\mathrm{pu}]$ \\
\hline$Q_{i, t}^{G}$ & Reactive power generated/consumed at bus $i$ in period $t[\mathrm{pu}]$. \\
\hline$Q_{l, t}^{r}$ & $\begin{array}{l}\text { Reactive power flow at receiving end of line } l \text { in period } t \\
\text { [pu]. }\end{array}$ \\
\hline$S O E_{i, t}^{S S}$ & $\begin{array}{l}\text { SOE of the shared storage system connected to bus } i \text { in } \\
\text { period } t[\mathrm{pu}] \text {. }\end{array}$ \\
\hline$T_{h, t}^{d e c}$ & $\begin{array}{l}\text { Indoor temperature decrease with respect to the user-selected } \\
\text { set-point in house } h \text { in period } t\left[{ }^{\circ} \mathrm{C}\right] .\end{array}$ \\
\hline$T_{h, t}^{i n}$ & Indoor temperature of house $h$ in period $t\left[{ }^{\circ} \mathrm{C}\right]$ \\
\hline$T_{h, t}^{i n c}$ & $\begin{array}{l}\text { Indoor temperature increase with respect to the user-selected } \\
\text { set-point in house } h \text { in period } t\left[{ }^{\circ} \mathrm{C}\right] .\end{array}$ \\
\hline$T_{h, t}^{s e t}$ & Thermostat set-point of house $h$ in period $t\left[{ }^{\circ} \mathrm{C}\right]$ \\
\hline$u_{h, t}$ & $\begin{array}{l}\text { Binary variable for the HVAC unit status of house } h \\
\text { connected in period } t(0=\mathrm{OFF}, 1=\mathrm{ON}) \text {. }\end{array}$ \\
\hline$u_{i, t}^{c h}$ & $\begin{array}{l}\text { Binary variable - } 1 \text { if shared storage system connected to bus } \\
i \text { is charging in period t, } 0 \text { else. }\end{array}$ \\
\hline$V_{i, t}$ & Voltage magnitude at bus $i$ in period $t[\mathrm{pu}]$ \\
\hline$W_{i, t}$ & $\begin{array}{l}\text { Equivalent to the cosine term of power flow equation over } \\
\text { line }(i, j) \text { in period } t[\mathrm{pu}] \text {. }\end{array}$ \\
\hline$W_{r, t}$ & $\begin{array}{l}\text { Square of the voltage magnitude at receiving bus } r(r \in i) \text { in } \\
\text { period } t[\mathrm{pu}] \text {. }\end{array}$ \\
\hline$\lambda_{h, t}^{x}$ & $\begin{array}{l}\text { Lagrange multipliers of lower-level problem constraints, } \\
\text { where } x=\{1, \ldots, 6\} \text {. }\end{array}$ \\
\hline
\end{tabular}

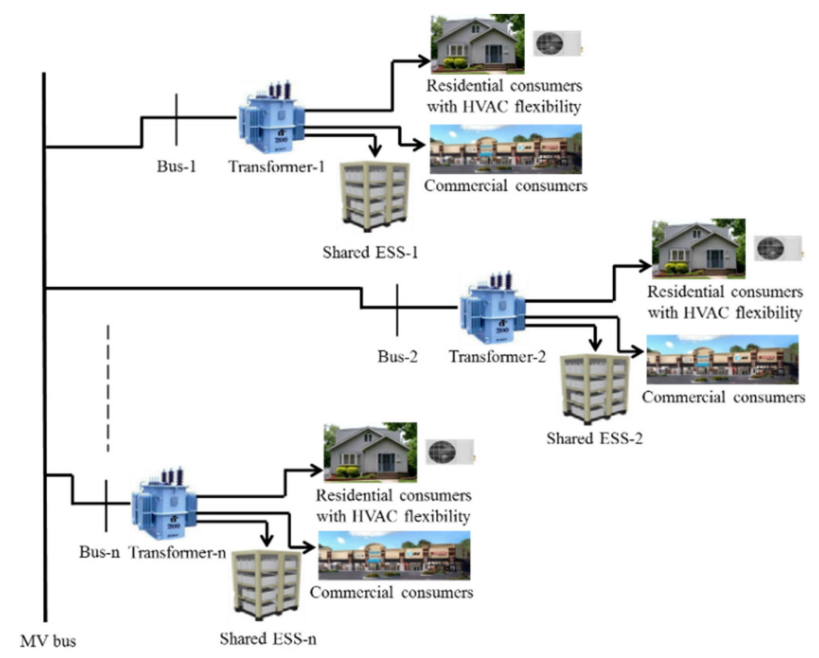

Fig. 1. Illustration of the considered distribution system consisting of various end-user types and shared ESS.

should be noted that the effects of the incentive mechanism are out of the scope of the study. Nonetheless, the interested reader is addressed to an exhaustive survey which provides real-world examples of the application of different incentive mechanisms [38].
The optimization problem is cast in the framework of bi-level optimization and is represented by (1)-(25).

$$
\text { Minimize } L=\sum_{t_{1}}^{t_{2}} \sum_{i} P_{i, t}^{S}
$$

subject to:

$$
\begin{aligned}
& P_{i, t}^{G}-P_{i, t}^{L}=\sum_{l \in B_{l}^{i j}}\left(M_{i, l}^{F} \cdot P_{l, t}^{r}+M_{i, l}^{L} \cdot P_{l, t}^{\text {loss }}\right) \forall i, t \\
& \begin{array}{l}
Q_{i, t}^{G}-Q_{i, t}^{L} \\
\quad=\sum_{l \in B_{l}^{i j}}\left(M_{i, l}^{F} \cdot Q_{l, t}^{r}+M_{i, l}^{L} \cdot Q_{l, t}^{l o s s}-B_{l} \cdot M_{l, i}^{W} \cdot W_{i, t}\right) \quad \forall i, t
\end{array}
\end{aligned}
$$

$P_{i, t}^{G}=P_{i, t}^{S S, d i s}+P_{i, t}^{S} \forall i, t$

$P_{i, t}^{L}=P_{i, t}^{L, o t h e r}+P_{i, t}^{S S, c h}+\sum_{h \in B_{h}^{i}} P_{h, t}^{A C} \forall i, t$

$P_{l, t}^{\text {loss }}=2 \cdot R_{l} \cdot \hat{P}_{l, t}^{\text {loss }} \forall l, t$

$X_{l} \cdot P_{l, t}^{\text {loss }}-R_{l} \cdot Q_{l, t}^{\text {loss }}=0 \forall l, t$

$\sum_{i}\left(M_{l, i}^{W} \cdot W_{i, t}\right)-2 \cdot\left(R_{l} \cdot P_{l, t}^{r}+X_{l} \cdot Q_{l, t}^{r}\right)$

$$
=R_{l} \cdot P_{l, t}^{\text {loss }}+X_{l} \cdot Q_{l, t}^{\text {loss }} \forall l, t
$$

$2 \cdot \hat{P}_{l, t}^{\text {loss }} \cdot W_{i, t} \geq P_{l, t}^{r 2}+Q_{l, t}^{r 2} \forall l, t$

$V_{\min }^{2} \leq W_{i, t} \leq V_{\max }^{2} \forall i, t$

$0 \leq P_{i, t}^{S S, c h} \leq R_{i}^{S S, c h} \cdot u_{i, t}^{c h} \forall i, t$

$0 \leq P_{i, t}^{S S, d i s} \leq R_{i}^{S S, d i s} \cdot\left(1-u_{i, t}^{c h}\right) \forall i, t$

$S O E_{i, t}^{S S}=S O E_{i,(t-1)}^{S S}+\left(C E_{i}^{S S} \cdot P_{i, t}^{S S, c h}-\frac{P_{i, t}^{S S, d i s}}{D E_{i}^{S S}}\right)$

$$
\times \Delta \mathrm{T} \forall i, t
$$

$S O E_{i}^{S S, \text { min }} \leq S O E_{i, t}^{S S} \leq S O E_{i}^{S S, \text { max }} \forall i, t$

$S O E_{i, 1}^{S S}=S O E_{i}^{S S, i n i} \forall i$

$T_{h, t}^{i n}=\left(1-\frac{\Delta \mathrm{T}}{1000 \cdot M_{h} \cdot c_{a} \cdot R_{h}^{e q}}\right) \cdot T_{h,(t-1)}^{i n}$

$$
+\frac{\Delta \mathrm{T}}{1000 \cdot M_{h} \cdot c_{a} \cdot R_{h}^{e q}} \cdot T_{t-1}^{a}
$$$$
-\frac{C O P_{h} \cdot \Delta \mathrm{T}}{0.000277 \cdot M_{h} \cdot c_{a}} \cdot P_{h, t}^{A C} \forall h, t>1
$$

$T_{h, 1}^{i n}=T_{h}^{1} \forall h$

$P_{h, t}^{A C}=u_{h, t} \cdot K_{h} \forall h, t$

$T_{h, t}^{i n} \forall h, t \in \underset{T_{h, t}^{i n c}, T_{h, t}^{d e c}, T_{h, t}^{s e t}, T_{h, t}^{i n}}{\operatorname{argmin}}\left\{\frac{1}{N^{h}} \cdot \sum_{h} \sum_{t}\left(T_{h, t}^{i n c}+T_{h, t}^{d e c}\right)\right.$ 
subject to:

$$
\begin{aligned}
& T_{h, t}^{s e t} \leq T_{h, t}^{d e s}+T_{h, t}^{i n c} \forall h, t: \lambda_{h, t}^{1} \\
& -T_{h, t}^{\text {set }} \leq T_{h, t}^{\text {dec }}-T_{h, t}^{\text {des }} \forall h, t: \lambda_{h, t}^{2} \\
& T_{h, t}^{i n} \leq T_{h, t}^{s e t}+T_{h}^{D B} \forall h, t: \lambda_{h, t}^{3} \\
& -T_{h, t}^{i n} \leq T_{h}^{D B}-T_{h, t}^{s e t} \forall h, t: \lambda_{h, t}^{4} \\
& -T_{h, t}^{d e c} \leq 0 \forall h, t: \lambda_{h, t}^{5} \\
& \left.-T_{h, t}^{i n c} \leq 0 \forall h, t: \lambda_{h, t}^{6} \sum_{h}\right\}
\end{aligned}
$$

The objective of the proposed optimization problem is to minimize the energy that is supplied by the grid and is calculated as the sum of the power drawn from all the buses during the DR event as indicated by (1). The active and reactive power balance equations are represented by (2) and (3), respectively. The power that is rendered available at each bus is decomposed to the contribution of the shared ESS in terms of discharging available energy and the injection of the local transformer by (4). Similarly, (5) enforces the fact that the system load comprises inelastic demand, the charging requirements of shared storage systems, as well as the HVAC demand. Constraints (6)-(9), which are extracted from [39] with relevant modifications, constitute a second order conic programming representation of the AC power flow equations, while (10) limits the voltage at each bus of the system between specified lower and upper limits. The operation of the storage system is described by (11)-(15).

In general, the energy consumption of HVACs depends on the temperature in the interior of the houses, which in turn is affected by various factors such as the heat exchange between the houses and ambient, the thermodynamic properties of building structure and thermal properties of air. In this study, a thermal resistance based model is used for the building as expressed by (16). The initial indoors temperature is set using constraint (17). The equivalent building thermal resistance and the air mass inside the building can be calculated using the (26)-(28). It is to be noted that a rectangular geometry and a roof inclination of $\beta^{\circ}$ are considered for simplicity. Finally, the HVAC power consumption of each household $h$ in each time interval $t$ follows (18).

$$
\begin{aligned}
R_{h}^{e q} & =\frac{1}{N} \sum_{e} \frac{l_{e, h}}{\sigma_{e, h} \cdot \mathrm{A}_{e, h}} \forall h \\
V_{h} & =L 1_{h} \cdot L 2_{h} \cdot L 3_{h}+\tan \left(\beta_{h}\right) \cdot L 1_{h} \cdot L 2_{h} \forall h \\
M_{h} & =V_{h} \cdot \delta_{\text {air }} \forall h
\end{aligned}
$$

In this study it considered that the LSE has the capability of directly controlling the thermostat temperature set-point of HVACs in order to achieve targets related to the optimal operation of the distribution system. For this purpose, the temperature set-point $T_{h, t}^{\text {set }}$ can be manipulated within some pre-defined limits with respect to the end-user desired set-point $T_{h, t}^{\text {des }}$. However, in order to prevent the discomfort of individual end-users due to prolonged interruptions, the control of the HVAC units should be subject to the minimization of the discomfort level of the end-users defined as the summation of the positive and negative temperature set-point deviations with respect to the selected one over time, averaged over the number of participating units, as defined in the objective function (19) of the lower-level optimization problem. This optimization problem is subject to constraints that define the increase or decrease of the parametrically bounded lower and upper temperature limits in order not to exceed the permitted end-user comfort preferences, as specified in the contract with the LSE, as expressed by (20) and (21), and the internal temperature limits with respect to the set-point, using dead-band control, as stated in (22) and (23). Finally, (24) and (25) are the non-negativity constraints for the decision variable that expresses the amount by which the set-point can be manipulated.

$$
\begin{aligned}
\Lambda= & \frac{1}{N^{h}} \cdot \sum_{h} \sum_{t}\left(T_{h, t}^{i n c}+T_{h, t}^{d e c}\right) \\
& +\sum_{h} \sum_{t} \lambda_{h, t}^{1} \cdot\left(T_{h, t}^{s e t}-T_{h, t}^{d e s}-T_{h, t}^{i n c}\right) \\
& +\sum_{h} \sum_{t} \lambda_{h, t}^{2} \cdot\left(-T_{h, t}^{s e t}-T_{h, t}^{d e c}+T_{h, t}^{d e s}\right) \\
& +\sum_{h} \sum_{t} \lambda_{h, t}^{3} \cdot\left(T_{h, t}^{i n}-T_{h, t}^{s e t}-T_{h}^{D B}\right) \\
& +\sum_{h} \sum_{t} \lambda_{h, t}^{4} \cdot\left(-T_{h, t}^{i n}-T_{h}^{D B}+T_{h, t}^{s e t}\right) \\
& +\sum_{h} \sum_{t}\left(-\lambda_{h, t}^{5} \cdot T_{h, t}^{d e c}\right) \\
& +\sum_{h} \sum_{t}\left(-\lambda_{h, t}^{6} \cdot T_{h, t}^{i n c}\right)
\end{aligned}
$$

With the objective of solving the bi-level optimization problem, the lower-level problem is replaced by its Karush-KuhnTucker (KKT) optimality conditions which in this case are both necessary and sufficient (linear and continuous lower-level problem).

To derive the KKT conditions, first, the Lagrange function of the optimization problem (29) is formed.

The variables $\lambda_{h, t}^{\xi}, \xi=1, \ldots, 6$ are the Lagrange multipliers associated with constraints (20)-(25), respectively.

The stationarity conditions are expressed by (30)-(33).

$$
\begin{aligned}
\frac{\partial \Lambda}{\partial T_{h, t}^{i n c}} & =0 \rightarrow \frac{1}{N^{h}}-\lambda_{h, t}^{1}-\lambda_{h, t}^{6}=0 \forall h, t \\
\frac{\partial \Lambda}{\partial T_{h, t}^{d e c}} & =0 \rightarrow \frac{1}{N^{h}}-\lambda_{h, t}^{2}-\lambda_{h, t}^{5}=0 \forall h, t \\
\frac{\partial \Lambda}{\partial T_{h, t}^{s e t}} & =0 \rightarrow \lambda_{h, t}^{1}-\lambda_{h, t}^{2}-\lambda_{h, t}^{3}+\lambda_{h, t}^{4}=0 \forall h, t \\
\frac{\partial \Lambda}{\partial T_{h, t}^{i n}} & =0 \rightarrow \lambda_{h, t}^{3}-\lambda_{h, t}^{4}=0 \forall h, t
\end{aligned}
$$

The complementary slackness conditions are given by (34)-(39). Note that these are non-linear constraints. One way 
TABLE IV

Line PARAMETERS OF the CONSIDERED 6-Bus Distribution System

\begin{tabular}{lllll}
\hline Line & From & To & R [pu] & $\mathbf{X}[\mathbf{p u}]$ \\
\hline L1 & n2 & n1 & 0.00071 & 0.00036 \\
L2 & n3 & n2 & 0.00017 & 0.00009 \\
L3 & n4 & n3 & 0.00153 & 0.00051 \\
L4 & n4 & n5 & 0.00035 & 0.00012 \\
L5 & n5 & n6 & 0.00133 & 0.00044 \\
\hline
\end{tabular}

TABLE V

Structural Parameters of THE HOUSEHOLdS

\begin{tabular}{|c|c|c|c|c|c|}
\hline Parameter & Value & Units & Parameter & Value & Units \\
\hline Length $\left(L_{1}\right)$ & 35 & $\mathrm{~m}$ & Number of windows & 7 & - \\
\hline Width $\left(L_{2}\right)$ & 12 & $\mathrm{~m}$ & Window length & 1 & $\mathrm{~m}$ \\
\hline Height $\left(L_{3}\right)$ & 4 & $\mathrm{~m}$ & Window width & 1 & $\mathrm{~m}$ \\
\hline Wall thickness & 0.11 & $\mathrm{~m}$ & Windows thickness & 0.05 & $\mathrm{~m}$ \\
\hline $\begin{array}{l}\text { Wall thermal } \\
\text { coefficient }\end{array}$ & 131 & $\mathrm{~J} / \mathrm{h} \cdot \mathrm{m} \cdot{ }^{\circ} \mathrm{C}$ & $\begin{array}{l}\text { Window thermal } \\
\text { coefficient }\end{array}$ & 2688 & $\mathrm{~J} / \mathrm{h} \cdot \mathrm{m} \cdot{ }^{\circ} \mathrm{C}$ \\
\hline Roof angle $(\beta)$ & 40 & deg & & & \\
\hline
\end{tabular}

to linearize them is to use a big-M formulation as in [40].

$$
\begin{aligned}
& \lambda_{h, t}^{1} \cdot\left(T_{h, t}^{s e t}-T_{h, t}^{\text {des }}-T_{h, t}^{i n c}\right)=0 \forall h, t \\
& \lambda_{h, t}^{2} \cdot\left(-T_{h, t}^{s e t}-T_{h, t}^{\text {dec }}+T_{h, t}^{d e s}\right)=0 \forall h, t \\
& \lambda_{h, t}^{3} \cdot\left(T_{h, t}^{i n}-T_{h, t}^{s e t}-T_{h}^{D B}\right)=0 \forall h, t \\
& \lambda_{h, t}^{4} \cdot\left(-T_{h, t}^{i n}-T_{h}^{D B}+T_{h, t}^{s e t}\right)=0 \forall h, t \\
& \lambda_{h, t}^{5} \cdot T_{h, t}^{d e c}=0 \forall h, t \\
& \lambda_{h, t}^{6} \cdot T_{h, t}^{i n c}=0 \forall h, t
\end{aligned}
$$

Finally, in order to guarantee dual feasibility, the Lagrange multipliers must be non-negative (40), while for primal feasibility (20)-(25) of the original problem are also enforced.

$$
\lambda_{h, t}^{1}, \lambda_{h, t}^{2}, \lambda_{h, t}^{3}, \lambda_{h, t}^{4}, \lambda_{h, t}^{5}, \lambda_{h, t}^{6} \geq 0 \forall h, t
$$

The optimization problem that needs to be solved can be now re-cast as a second order conic programming problem. Objective function (1) is minimized subject to (2)-(18), (20)-(25), (30)-(40), considering also the constraints required in order to approximate the non-linear expressions (34)-(39).

\section{RESULTS AND DISCUSSION}

\section{A. Input Data}

The system that is considered consists of $6 \mathrm{LV}$ buses. The line parameters are shown in Table IV. These parameters are expressed in per unit $\mathrm{pu}$ ) values with a base for apparent power of $1 \mathrm{MVA}$, a base for voltage of $20 \mathrm{kV}$ and a base for impedance of $400 \Omega$. For the sake of simplicity, it is assumed that all the households connected through these lines are located in the same region. Thus, the parameters related to the properties of air required for the calculation of thermal interactions between the houses and ambient are considered constant and the standard values $\delta_{a i r}=1.225 \mathrm{kgm}^{3}$ and $c_{a}=1.01 \mathrm{~kJ} / \mathrm{kg}^{\circ} \mathrm{C}$ are used. Similarly, it is assumed that all the households have the identical structural parameters, as shown in Table $\mathrm{V}$ and are equipped with the same HVAC unit that has a power rating of $2.4 \mathrm{~kW}$ and a coefficient-of-performance (COP) of 1.5. The parameters
TABLE VI

Parameters Characterizing the Preferences of THE END-Users

\begin{tabular}{lll}
\hline Parameter & Value & Units \\
\hline$T_{h, t}^{\text {des }}$ & 20 & ${ }^{0} \mathrm{C}$ \\
$T_{h}^{\text {dec_allowed }}$ & 4 & ${ }^{0} \mathrm{C}$ \\
$T_{h}^{\text {inc_allowed }}$ & 4 & ${ }^{0} \mathrm{C}$ \\
$T_{h}^{D B}$ & \pm 0.8 & ${ }^{0} \mathrm{C}$ \\
\hline
\end{tabular}

TABLE VII

Parameters of THE SHared ENERgy StORAGe System

\begin{tabular}{lll|lll}
\hline Parameter & Value & Units & Parameter & Value & Units \\
\hline$C E_{i}^{S S}$ & 0.95 & - & $S O E_{i}^{S S, \text { in } i}$ & 0.12 & $\mathrm{pu}$ \\
$D E_{i}^{S S}$ & 0.95 & - & $S O E_{i}^{S S, \min }$ & 0.05 & $\mathrm{pu}$ \\
$R_{i}^{S S, \text {, } h}$ & 0.1 & $\mathrm{pu}$ & $S O E_{i}^{S S, \max }$ & 0.2 & $\mathrm{pu}$ \\
$R_{i}^{S S, \text { dis }}$ & 0.1 & $\mathrm{pu}$ & & & \\
\hline
\end{tabular}

characterizing the end-users' preferences during the DR events are also given in Table VI. Moreover, the same user-selected temperature set-point value is adopted in this study for all houses and is considered to be constant during the DR event.

In practical implementations, the end-users may change their desired temperature set-point values in response to different daily temperature profiles by conveying their preferences to the LSE before the DR event is activated. In reality, the temperature that the end-users perceive depends on many physical and subjective factors in addition to the room temperature; however, the LSE has the capability of gathering the temperature data only for evaluating the average end-user comfort. Finally, an initial indoor temperature around the $T_{h, t}^{\text {des }}$ value is randomly chosen for each household taking also the predefined $T_{h}^{D B}$ range into account.

For the response to DR events, a time-span between $12 \mathrm{pm}$ and $4 \mathrm{pm}$ is assumed to have been accepted by all the contracted households. For the case study, a typical summer day is considered and the DR event is assumed to be realized between $1 \mathrm{pm}$ and $4 \mathrm{pm}$, with the aim of alleviating the high demand in this period. Nevertheless, the period between $12 \mathrm{pm}-1 \mathrm{pm}$ is also included in the simulation studies in order to observe the temperature variation in the houses and to examine the charging behavior of the shared ESS. The parameters related to the shared ESS connected at each bus are presented in Table VII. As it can be seen, charging and discharging rates of the shared ESS as well as the minimum and maximum state-of-energy (SOE) values are limited within pre-defined ranges in order to protect the shared ESS from inefficient operating conditions that might cause increased capacity degradation to the shared ESS.

Furthermore, the shared ESS units are assumed to be directly operated by the DSO. The parameters of these units are determined according to the total power consumption of the houses and the relevant criteria presented in the literature. As it has already been mentioned, a high capacity shared ESS unit may increase the benefits both for the DSO and the LSE. Nevertheless, an oversized shared ESS might be economically and operationally inefficient. As a result, the optimal ESS specifications should be determined by conducting a comprehensive preliminary analysis which considers a manifold of criteria, such 


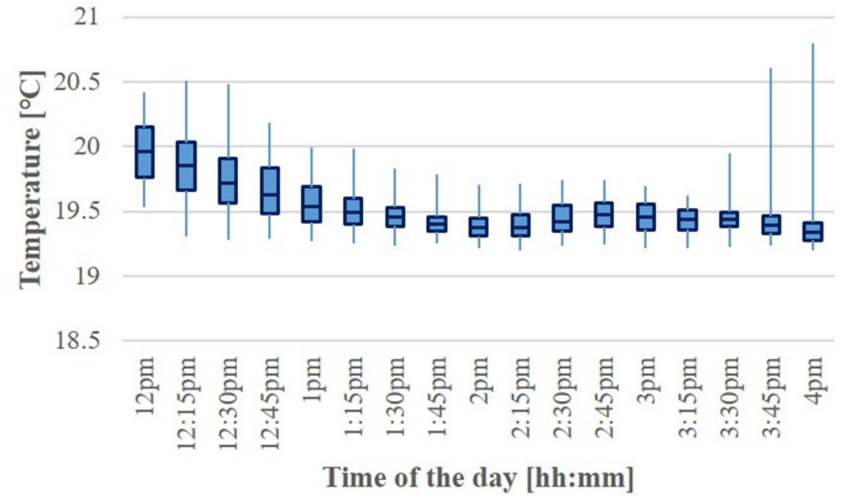

Fig. 2. The indoor temperature variations of households for Case-1.

as the capacity of the distribution system, the deployment and operational costs of ESS units and battery degradation.

\section{B. Simulation and Results}

In order to examine the benefits of the proposed approach, three different cases are considered:

- Case-1: The use of HVAC based solely on user-defined preferences without considering the occurrence of a DR event and the presence of a shared ESS unit.

- Case-2: The DLC of HVAC by LSE during a DR event without considering the presence of a shared ESS unit.

- Case-3: The DLC of HVAC by LSE during a DR event considering the presence of a shared ESS unit.

A time granularity of $5 \mathrm{~min}$ (i.e., $0.0833 \mathrm{~h}$ ) is used in all the three cases. The proposed model was implemented in the General Algebraic Modelling System (GAMS) version 24.1.3. and the optimization problems were solved using the MOSEK solver. The average solution time for a relative optimality gap of $0 \%$ is 0.5 seconds on a $2.3 \mathrm{GHz}$, quad-core i7 processor PC with $16 \mathrm{~GB}$ of RAM.

In the first case, the HVAC system is assumed to be controlled so that $T_{h, t}^{i n}$ value is maintained in the range of $T_{h, t}^{d e s} \pm T_{h}^{D B}$ during all the considered periods. This case aims only to ensure the end-user comfort without taking the objective function and the constraints (11)-(15), (20)-(25) and (30)-(40) into account, and is used for the comparisons with the proposed concepts to evaluate their contributions. In the second case, a reduction in the energy drawn from the grid is aimed to be achieved considering the objective function while neglecting the constraints (11)(15) and (30)-(40). As a result, the HVAC system is controlled by maintaining the $T_{h, t}^{i n}$ value within the predefined maximum allowed temperature set-point limits during the DR event. Including the shared ESS-related constraints and considering the end-user's comfort, the performance of the proposed bi-level optimization approach is investigated in Case-3. The indoor temperature variations of all the households connected to the different buses during the considered time period are shown in Figs. 2-4. In these figures, the middle horizontal line in the boxes represents the median of the temperature values of all the households, i.e., 240 houses in total connected to 6-buses, for the corresponding time of the day. The box spans the first and

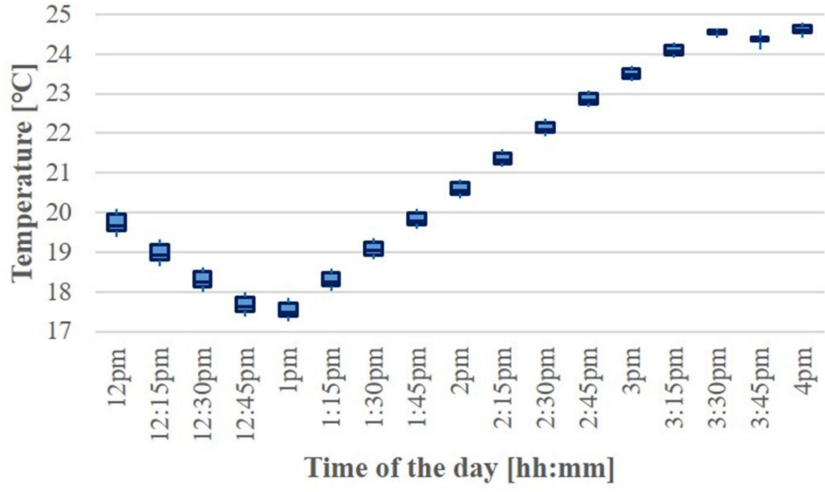

Fig. 3. The indoor temperature variations of households for Case-2.

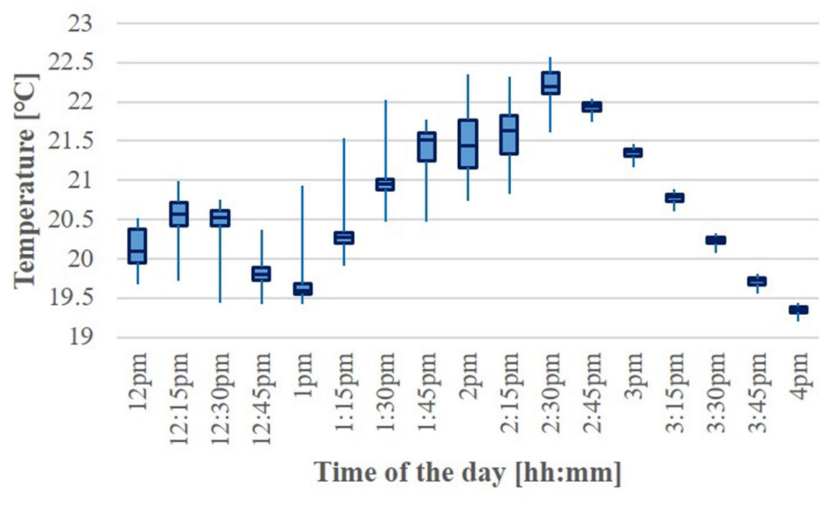

Fig. 4. The indoor temperature variations of households for Case-3.

third quartiles, which are below and above the median, respectively. The end of the vertical lines below and above the boxes shows the maximum and minimum temperature values.

It should be noted that the data averaged over $15 \mathrm{~min}$ time intervals are used for Figs. 2-4 in order to provide a clearer representation while still preserving the main characteristics of the temperature variations.

As shown in Fig. 2, the temperature values of each household are kept within the desired range in Case-1. In Case-2, the thermostat set-point of HVACs is first set to lower values than the corresponding indoor temperature of the houses before the initiation of the DR event and then set to higher values so that the power consumption is minimized during the DR event, which results in high deviations from the desired temperature values both before and during the DR event. As it can be noticed in Fig. 4, the temperature deviation of households in Case- 3 is limited to a relatively narrower range compared to Case- 2 due to the proposed bi-level optimization algorithm which takes into account the maximization of the end-users' comfort.

The power consumption of residential HVAC during the contracted DR period for all the case studies is depicted in Fig. 5. As seen from Fig. 5, first, it is evident that the HVAC units are used relatively frequently in most of the houses in Case- 1 in order to satisfy the desired temperature value defined by the end-users. In the second case, the HVAC units in all the houses are operated just before the period with highest energy consumption for cooling down the houses. 


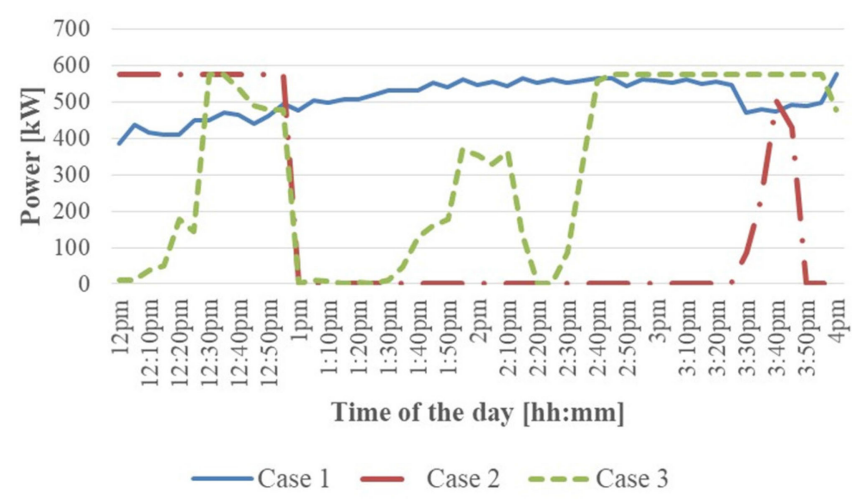

Fig. 5. The total HVAC power consumption before and during the DR event for the three cases.

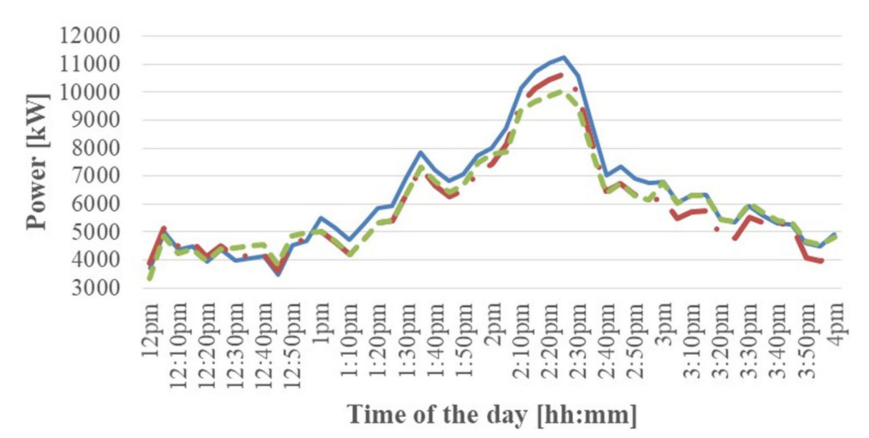

- Case 1 Case 2 - Case 3

Fig. 6. The power supplied by the grid including the losses before and during the DR event for the three cases.

All the HVACs are then turned off through controlling their thermostat set points at the beginning of the event for maximum power saving during the event. Nevertheless, they start to be used again before the end of the event since the indoor temperatures at this point reach to the allowed set-point increase level plus the dead-band limit. In Case- 3 in which the proposed optimization algorithm is used, first, the houses are cooled down similarly to Case- 2 but to relatively higher temperature values, imposed by the constraints defined to satisfy the objective of the latter objective function, which is the minimization of the end-users' discomfort level. With the same objective, some of the HVAC units are also used during the DR event, while all of them are operated in the second half of the event.

As stated before, each LV bus supplies energy to various commercial consumers and 40 households consisting of HVACs and inflexible appliances. The total power consumption of all the loads connected to the all buses together with the relevant line losses and the resulting power reductions due to the DR events are shown in Fig. 6. It is clear that limited use of a high number of HVAC units in Cases 2 and 3 enables a considerable loss reduction, especially during the intensive power consumption periods. The reason of the high consumption power values in Case- 3 after the peak demand, which occurs between $3 \mathrm{pm}$ and $4 \mathrm{pm}$, is the aim of maintaining an acceptable comfort level violation for the consumers. It should be noted that the shared ESS used in Case-3 also helps energy demand reduction at the

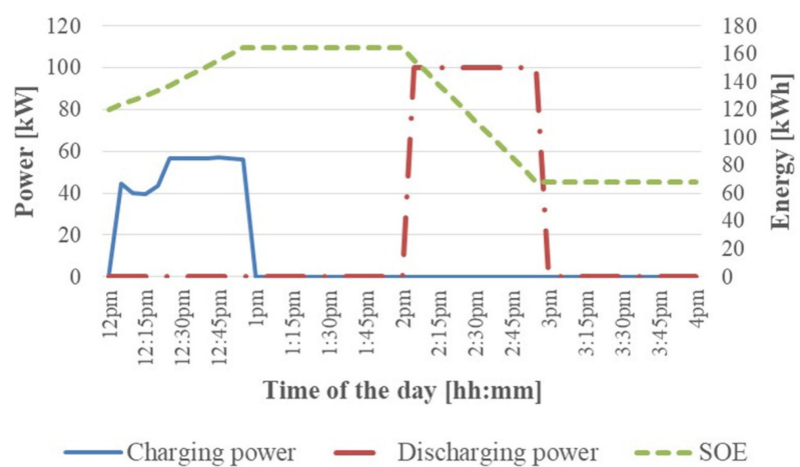

Fig. 7. The variations in battery characteristics before and during the DR event for Case-3.

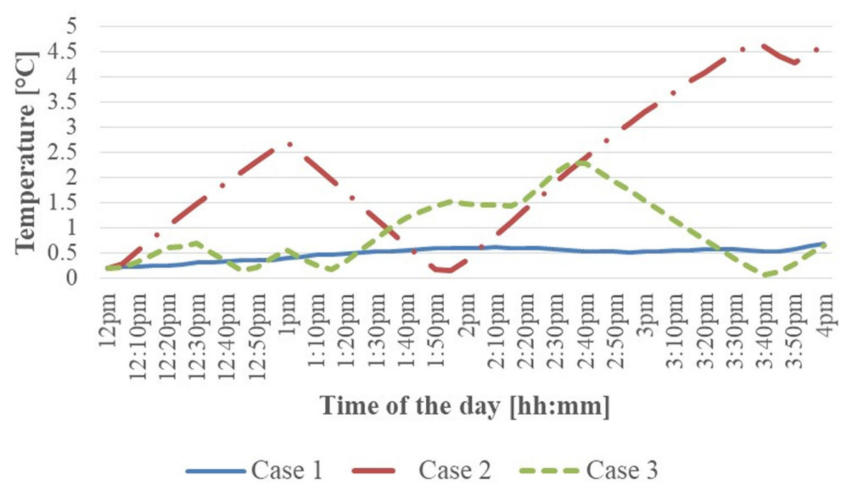

Fig. 8. The average comfort violation value before and during the DR event for the three cases.

cost of increasing the consumption levels before the event, i.e., between $12 \mathrm{pm}$ and $1 \mathrm{pm}$.

The average contribution of the shared ESS to the power consumption of the households during the time period considered in the case study is illustrated in Fig. 7. As seen, the shared ESS units are charged at their total maximum rate before the DR event and discharged when the highest demand is faced. However, in real-world applications, it might be a more effective method in terms of monetary savings to charge the shared ESS during the night times in which the energy prices are typically relatively lower in comparison with the prices around noontime. Similarly, the shared ESS can be also charged with the excess power generation of renewable energy sources if these systems are already available in the distribution network.

Regarding the comfort violation in terms of temperature deviations from the desired temperature values, the average values for Case- 3 are significantly lower compared to those obtained for Case-2, as shown in Fig. 8. It should be also noted that the average comfort violation is almost the same as that achieved in Case-1 except for the period around the highest load demand.

Finally, various summary results for the three cases examined are presented in Table VIII. As seen from the first column of Table VIII that provides the total energy drawn from the power grid during the whole simulation period (i.e., before and during the DR event), the implementation of DR programs considerably reduces the energy purchased from the grid. Due to the amount of the energy drawn from the grid to charge the battery just 
TABLE VIII

OVERVIEW OF THE OBTAINED RESULTS

\begin{tabular}{|c|c|c|c|c|c|}
\hline \multirow[t]{2}{*}{ Case } & \multirow{2}{*}{$\begin{array}{c}\text { Grid supplied } \\
\text { energy } \\
{[k W h]}\end{array}$} & \multirow{2}{*}{$\begin{array}{c}\text { Reduction in energy } \\
\text { consumption } \\
{[k W h]}\end{array}$} & \multicolumn{3}{|c|}{$\begin{array}{c}\text { Comfort violation } \\
{\left[{ }^{\circ} \mathrm{C} / 5 \mathrm{~min}\right]}\end{array}$} \\
\hline & & & $\min$ & $\max$ & average \\
\hline 1 & 25452 & 13143 & 0.21 & 0.68 & 0.49 \\
\hline 2 & 23964 & 12224 & 0.15 & 4.62 & 2.19 \\
\hline 3 & 24325 & 12119 & 0.07 & 2.29 & 0.91 \\
\hline
\end{tabular}

before the DR event, the supplied energy in Case-3 is higher than that in Case-2. However, it should be recalled that the main target of the proposed approach is to decrease the energy consumption as much as possible (without disturbing end-users considerably), a target that is more successfully achieved with respect to the results obtained for the other two cases, as seen from the second column of the Table VIII, in which a power over $7000 \mathrm{~kW}$ is considered as critical power.

It is important to highlight that the price of the energy during these periods is significantly higher than the prices in off-peak periods and therefore, drawing more energy outside of the peak demand periods does not necessarily increase the total cost of the energy used.

Regarding the other important target of the proposed approach, it is evident that the bi-level optimization problem significantly prevents the deterioration of the comfort level of the end-users by limiting the deviations from their desired temperature set-points as presented in the third column of Table VIII, while still accomplishing a reduction in the total energy during the considered energy-intensive period. In addition to the main benefits the proposed algorithm it is interesting to notice that it also has side benefits such as preventing the load recovery effect, in other words, the occurrence of a rebound peak load demand due to increasing the consumption in the periods immediately following the DR event in order to recover the desired comfort levels. Considering the narrow indoor temperature changes given in Table VIII and the fact that the indoor temperature of all the households is kept around (even below) the desired temperature levels as shown in Fig. 4, it can be indicated that no load recovery effect will be faced after the ending time of the DR event in Case- 3 , in contrast to Case-2.

In order to examine the scalability of the proposed approach, the same concept is applied to a larger distribution system consisting of $12 \mathrm{LV}$ buses each of which has a shared ESS and supplies 40 houses with energy. The same physical specifications for the houses and ESS units given in Tables V-VII are used.

Regarding the parameters of the lines, the values of Table IV are used for the first six lines, while the parameters of the six additional lines are given in Table IX.

The statistical description of the indoor temperature variations of the households connected to the 12 buses is shown in Figs. 9-11. As it can be seen in Figs. 9-11, the similar indoor temperature profiles are obtained for the extended distribution system compared to the 6-bus system.

In Case-1, a relatively stable temperature is maintained for most of the houses as shown in Fig. 9, and in Cases 2 and 3, the
TABLE IX

Line PARAMETERS OF THE CONSIDERED 12-Bus Distribution System

\begin{tabular}{lllll}
\hline Line & From & To & R [pu] & X [pu] \\
\hline L6 & n6 & n7 & 0.00101 & 0.00054 \\
L7 & n7 & n8 & 0.00057 & 0.00029 \\
L8 & n8 & n9 & 0.00044 & 0.00021 \\
L9 & n9 & n10 & 0.00112 & 0.00036 \\
L10 & n10 & n11 & 0.00119 & 0.00056 \\
L11 & n11 & n12 & 0.00199 & 0.00087 \\
\hline
\end{tabular}

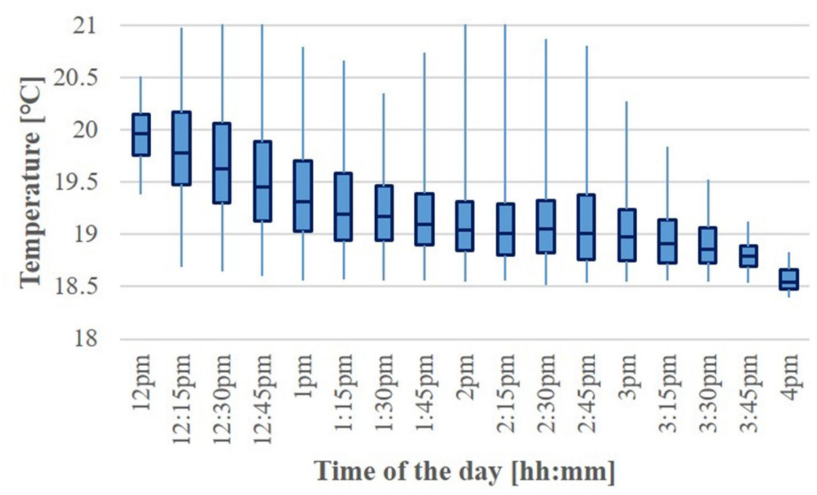

Fig. 9. The indoor temperature variations of households for Case-1 (12-bus system).

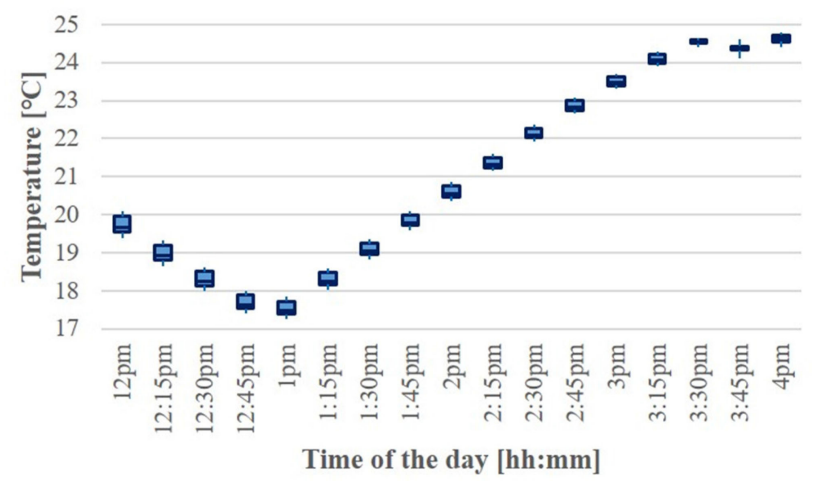

Fig. 10. The indoor temperature variations of households for Case-2 (12-bus system).

indoor temperatures tend to decrease before the starting time of the DR event and then to increase during the DR event due to the applied optimization algorithms for achieving higher benefits from the DR event. This tendency may also be observed in Fig. 12, which shows that all the HVAC units are used before the DR event and only some of them are used during the DR event for Cases 2 and 3 contrary to Case- 1 where the HVAC usage is determined only according to the user-defined temperature set values.

Similar to the results presented for the 6-bus system, Fig. 13 shows that a relatively lower power consumption is achieved for Cases 2 and 3 by avoiding the use of a high number of HVAC units during the DR period. It may also be seen in Fig. 13 that higher power is drawn from the grid before the DR event for Case-3, which is caused by the charging of the shared ESS units for using the stored energy during the DR event. These power exchanges between the shared ESS units and the grid, as well as the corresponding variations in the SOE of the shared ESS units 


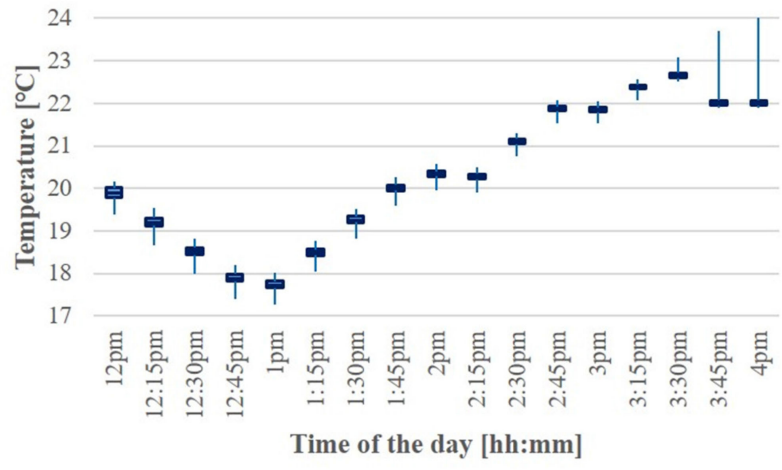

Fig. 11. The indoor temperature variations of households for Case-3 (12-bus system).

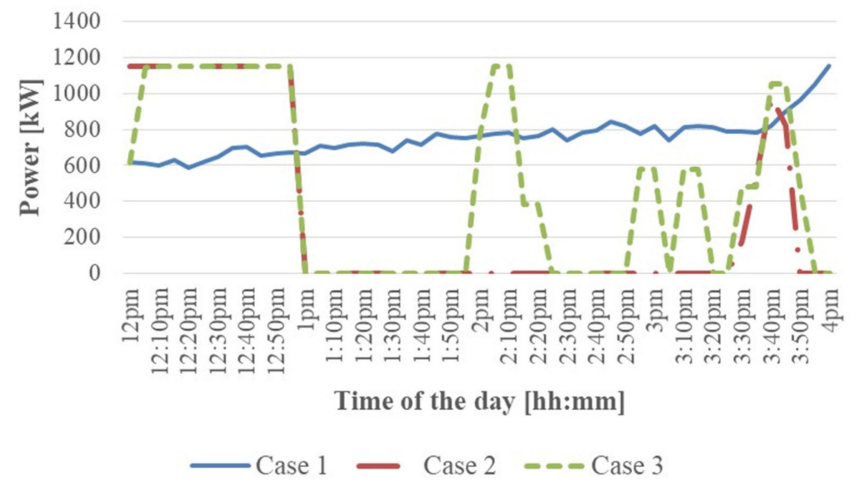

Fig. 12. The total HVAC power consumption before and during the DR event for the the three cases (12-bus system).

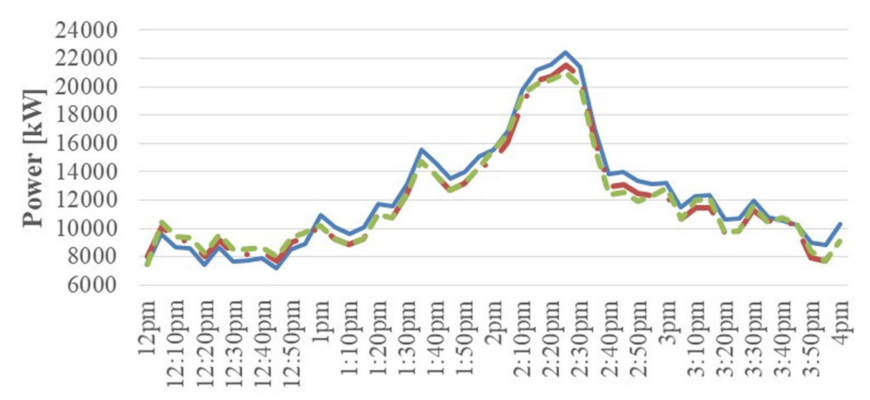

Time of the day [hh:mm]

- Case 1 Case 2 - - Case 3

Fig. 13. The power supplied by the grid including the losses before and during the DR event for the three cases (12-bus system).

are depicted in Fig. 14. Lastly, the average comfort violation for three cases is shown in Fig. 15 for the 12-bus system.

The values in Fig. 15 confirm that the proposed approach affects the end-users-comfort to a lower extent compared to Case-2. The level of the comfort violation and the obtained energy reduction for the 12-bus distribution system are presented in Table X.

Lastly, it is worth mentioning that in the case studies that were considered in this work, all the end-users were assumed to successfully respond to DR events. Evidently, in real-world applications, it is possible that a number of end-users would override the DLC-based DR control and therefore decline to

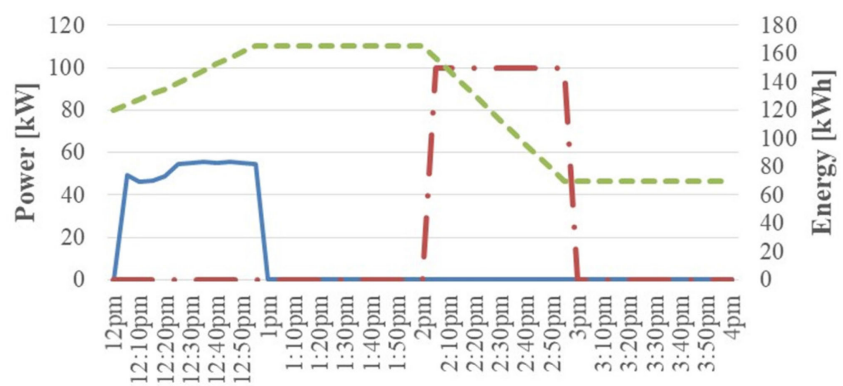

Time of the day [hh:mm]

—Charging power — Discharging power $---\mathrm{SOE}$

Fig. 14. The variations in battery operational characteristics before and during the DR event for Case-3 (12-bus system).

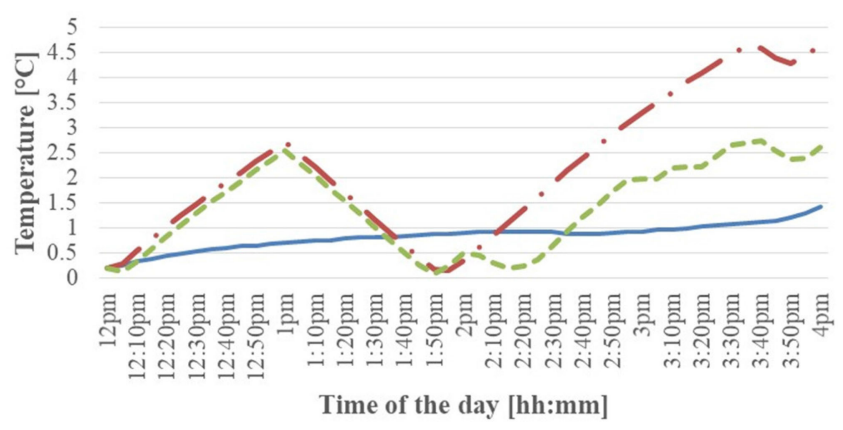

- Case 1 Case 2 - Case 3

Fig. 15. The average comfort violation value before and during the DR event for the three cases (12-bus system).

TABLE X

OVERVIEW OF THE OBTAINED RESULTS FOR 12-BUS SYSTEM

\begin{tabular}{|c|c|c|c|c|c|}
\hline \multirow[t]{2}{*}{ Case } & \multirow{2}{*}{$\begin{array}{c}\text { Grid supplied } \\
\text { energy } \\
{[k W h]}\end{array}$} & \multirow{2}{*}{$\begin{array}{c}\text { Reduction in energy } \\
\text { consumption } \\
{[k W h]}\end{array}$} & \multicolumn{3}{|c|}{$\begin{array}{c}\text { Comfort violation } \\
{\left[{ }^{\circ} \mathrm{C} / 5 \mathrm{~min}\right]}\end{array}$} \\
\hline & & & $\min$ & $\max$ & average \\
\hline 1 & 49870 & 25772 & 0.21 & 1.43 & 0.83 \\
\hline 2 & 47952 & 24451 & 0.15 & 4.62 & 2.19 \\
\hline 3 & 48233 & 24317 & 0.09 & 2.73 & 1.42 \\
\hline
\end{tabular}

respond to the DR event. This assumption may be justified on the basis of two factors: 1) it is less likely that end-users will override a DLC-based DR control due to the design of the relevant contracts [38], and, 2) practical evidence suggests that DR resources can offer a statistically reliable response [41]. Though, it is interesting to discuss the challenges that might be faced while applying the proposed approach as a function of the number of responding end-users: 1) similarly to all the DR programs that aim to aggregate the response of a large number of small consumers, the effectiveness of the proposed optimization method might decrease considerably if a large number of enrolled end-users decline to respond in a DR event, and, 2) in case of a relatively higher end-user participation, the capacity of ESS unit might not be sufficient to compensate for the required energy consumption during the highest demand periods. 


\section{CONClusions AND Future Work}

A bi-level optimization problem aiming at exploiting the flexibility from both DR programs based on DLC of HVAC units and shared ESS was presented in study for the reduction of load demand during DR event periods without deteriorating the enduser comfort. The results have showed that shared ESS units have the capability of supporting the use of HVAC units during the DR events, while still decreasing the amount of energy that is supplied from the grid. In addition to that, the deployment of ESS has resulted in an increase in the average comfort level of end-users compared to the conventional DR programs focusing on only reduction in energy consumption. In terms of percentage improvements, the end-user comfort-oriented optimization problem provides a decrement of $22 \%$ in the energy demand originating from residential electrical energy consumption compared to the case in which HVAC units are controlled based solely on end-users' preferences, and $8 \%$ compared to the case in which a DR program aiming at decreasing the energy reduction only is adopted. At the same time, the average comfort violation of end-users is reduced by $58 \%$ compared to the case based on the mentioned single-objective DR program. As a future study, the effectiveness of the proposed approach will be investigated for a longer time period in order to examine the effects of different ambient temperature profiles and userdefined parameters on the performance of the proposed strategy. Besides, the benefits of the proposed algorithm will be investigated for the case in which a number of households are equipped with rooftop PV systems. Also, different types of control techniques such as the direct compressor control mechanism might be considered for the control of HVAC operation. It should also be noted that battery-based shared ESS are used in this study due to their easy and relatively low-cost installation and decommissioning; however, any kind of electric energy storage devices such as flywheels and ultra-capacitors can be effectively exploited to achieve similar objectives.

\section{REFERENCES}

[1] A. H. Mohsenian-Rad, V. W. S. Wong, J. Jatskevich, R. Schober, and A. Leon-Garcia, "Autonomous demand-side management based on gametheoretic energy consumption scheduling for the future smart grid," IEEE Trans. Smart Grid, vol. 1, no. 3, pp. 320-331, Dec. 2010.

[2] C. A. Hill, M. C. Such, D. Chen, J. Gonzalez, and W. M. Grady, "Battery energy storage for enabling integration of distributed solar power generation," IEEE Trans. Smart Grid, vol. 3, no. 2, pp. 850-857, Jun. 2012.

[3] K. J. Chua, S. K. Chou, W. M. Yang, and J. Yan, "Achieving better energy efficient air conditioning - A review of technologies and strategies," Appl. Energy, vol. 104, pp. 87-104, Apr. 2013.

[4] N. G. Paterakis, A. Taşcıkaraoğlu, O. Erdinç, A. G. Bakirtzis, and J. P. S. Catalão, "Assessment of demand-response-driven load pattern elasticity using a combined approach for smart households," IEEE Trans. Ind. Inf., vol. 12, no. 4, pp. 1529-1539, Aug. 2016.

[5] H. T. Haider, O. H. See, and W. Elmenreich, "A review of residential demand response of smart grid," Renewable Sustain. Energy Rev., vol. 59, pp. 166-178, Jun. 2016.

[6] O. Elma, A. Taşcıkaraoğlu, A. T. İnce, and U. S. Selamoğulları, "Implementation of a dynamic energy management system using real time pricing and local renewable energy generation forecasts," Energy, vol. 134, pp. 206-220, Sep. 2017.

[7] L. Zhu, Z. Yan, W. J. Lee, X. Yang, Y. Fu, and W. Cao, "Direct load control in microgrids to enhance the performance of integrated resources planning," IEEE Trans. Ind. Appl., vol. 51, no. 5, pp. 3553-3560, Sep./Oct. 2015.
[8] O. Erdinç, A. Taşcıkaraoğlu, N. G. Paterakis, Y. Eren, and J. P. S. Catalão, "End-user comfort oriented day-ahead planning for responsive residentia HVAC demand aggregation considering weather forecasts," IEEE Trans. Smart Grid, vol. 8, no. 1, pp. 362-372, Jan. 2017.

[9] K. Rahbar, M. R. V. Moghadam, S. K. Panda, and T. Reindl, "Shared energy storage management for renewable energy integration in smart grid," in Proc. IEEE Power Energy Soc. Innov. Smart Grid Technol. Conf. Minneapolis, MN, USA, 2016, pp. 1-5.

[10] K. Paridari, A. Parisio, H. Sandberg, and K. H. Johansson, "Demand response for aggregated residential consumers with energy storage sharing," in Proc. 54th IEEE Conf. Decis. Control , Osaka, Japan, 2015, pp. 2024 2030.

[11] W. Tushar et al., "Energy storage sharing in smart grid: A modified auction-based approach," IEEE Trans. Smart Grid, vol. 7, no. 3, pp. 1462 1475, May 2016

[12] C. D. Korkas, S. Baldi, I. Michailidis, and E. B. Kosmatopoulos, "Occupancy-based demand response and thermal comfort optimization in microgrids with renewable energy sources and energy storage," Appl. Energy, vol. 163, pp. 93-104, Feb. 2016.

[13] A. Taşcıkaraoğlu, "Economic and operational benefits of energy storage sharing for a neighborhood of prosumers in a dynamic pricing environment," Sustain. Cities Soc., vol. 38, pp. 219-229, Apr. 2018.

[14] H. Kanchev, D. Lu, F. Colas, V. Lazarov, and B. Francois, "Energy management and operational planning of a microgrid with a PV-based active generator for smart grid applications," IEEE Trans. Ind. Electron., vol. 58, no. 10 , pp. 4583-4592, Oct. 2011.

[15] M. Sechilariu, B. Wang, and F. Locment, "Building integrated photovoltaic system with energy storage and smart grid communication," IEEE Trans. Ind. Electron., vol. 60, no. 4, pp. 1607-1618, Apr. 2013.

[16] K. Sun, L. Zhang, Y. Xing, and J. M. Guerrero, "A distributed control strategy based on dc bus signaling for modular photovoltaic generation systems with battery energy storage," IEEE Trans. Power Electron., vol. 26, no. 10, pp. 3032-3045, Oct. 2011

[17] A. Tascikaraoglu, A. R. Boynuegri, and M. Uzunoglu, "A demand side management strategy based on forecasting of residential renewable sources: A smart home system in Turkey," Energy Building, vol. 80, pp. 309-320, Sep. 2014.

[18] F. Ye, Y. Qian, and R. Q. Hu, "Energy efficient self-sustaining wireless neighborhood area network design for smart grid," IEEE Trans. Smart Grid, vol. 6, no. 1, pp. 220-229, Jan. 2015.

[19] S. Singla, Y. Ghiassi-Farrokhfal, and S. Keshav, "Using storage to minimize carbon footprint of diesel generators for unreliable grids," IEEE Trans. Sustain. Energy, vol. 5, no. 4, pp. 1270-1277, Oct. 2014.

[20] Y. Guo, M. Pan, Y. Fang, and P. P. Khargonekar, "Decentralized coordination of energy utilization for residential households in the smart grid,' IEEE Trans. Smart Grid, vol. 4, no. 3, pp. 1341-1350, Sep. 2013.

[21] N. G. Paterakis, O. Erdinç, I. N. Pappi, A. G. Bakirtzis, and J. P. S. Catalão, "Coordinated operation of a neighborhood of smart households comprising electric vehicles, energy storage and distributed generation," IEEE Trans. Smart Grid, vol. 7, no. 6, pp. 2736-2747, Nov. 2016.

[22] M. C. Bozchalui, S. A. Hashmi, H. Hassen, C. A. Canizares, and K. Bhattacharya, "Optimal operation of residential energy hubs in smart grids," IEEE Trans. Smart Grid, vol. 3, no. 4, pp. 1755-1766, Dec. 2012.

[23] L. Wang, D. H. Liang, A. F. Crossland, P. C. Taylor, D. Jones, and N S. Wade, "Coordination of multiple energy storage units in a low-voltage distribution network," IEEE Trans. Smart Grid, vol. 6, no. 6, pp. 2906 2918, Nov. 2015

[24] P. M. van de Ven, N. Hegde, L. Massoulié, and T. Salonidis, "Optimal control of end-user energy storage," IEEE Trans. Smart Grid, vol. 4, no. 2, pp. 789-797, Jun. 2013.

[25] C. P. Mediwaththe, E. R. Stephens, D. B. Smith, and A. Mahanti, "A Dynamic game for electricity load management in neighborhood area networks," IEEE Trans. Smart Grid, vol. 7, no. 3, pp. 1329-1336, May 2016.

[26] W. Tushar et al., "Three-party energy management with distributed energy resources in smart grid," IEEE Trans. Ind. Electron., vol. 62, no. 4, pp. 2487-2498, Apr. 2015.

[27] N. Good, E. Karangelos, A. Navarro-Espinosa, and P. Mancarella, "Optimization under uncertainty of thermal storage-based flexible demand response with quantification of residential users' discomfort," IEEE Trans. Smart Grid, vol. 6, no. 5, pp. 2333-2342, Sep. 2015.

[28] N. Jayasekara, M. A. S. Masoum, and P. J. Wolfs, "Optimal operation of distributed energy storage systems to improve distribution network load and generation hosting capability," IEEE Trans. Sustain. Energy, vol. 7, no. 1, pp. 250-261, Jan. 2016. 
[29] D. Wu, F. Tang, T. Dragicevic, J. C. Vasquez, and J. M. Guerrero, "A control architecture to coordinate renewable energy sources and energy storage systems in islanded microgrids," IEEE Trans. Smart Grid, vol. 6, no. 3, pp. 1156-1166, May 2015.

[30] H. Yang et al., "Distributionally robust optimal bidding of controllable load aggregators in the electricity market," IEEE Trans. Power Syst., vol. 33, no. 1, pp. 1089-1091, Jan. 2018.

[31] Z. Xu, Z. Hu, Y. Song, and J. Wang, "Risk-averse optimal bidding strategy for demand-side resource aggregators in day-ahead electricity markets," IEEE Trans. Smart Grid, vol. 8, no. 1, pp. 96-105, Jan. 2017.

[32] H. Yang, S. Zhang, J. Oiu, D. Qiu, M. Lai, and Z. Y. Dong, "CVaRconstrained optimal bidding of electric vehicle aggregators in day-ahead and real-time markets," IEEE Trans. Ind. Inf., vol. 13, no. 5, pp. 25552565, Oct. 2017.

[33] S. I. Vagropoulos, D. K. Kyriazidis, and A. G. Bakirtzis, "Real-time charging management framework for electric vehicle aggregators in a market environment," IEEE Trans. Smart Grid, vol. 7, no. 2, pp. 948-957, Mar. 2016.

[34] H. Wu, M. Shahidehpour, A. Alabdulwahab, and A. Abusorrah, "A game theoretic approach to risk-based optimal bidding strategies for electric vehicle aggregators in electricity markets with variable wind energy resources," IEEE Trans. Sustain. Energy, vol. 7, no. 1, pp. 374-385, Jan. 2016.

[35] L. Gkatzikis, I. Koutsopoulos, and T. Salonidis, "The role of aggregators in smart grid demand response markets," IEEE J. Sel. Areas Commun., vol. 31, no. 7, pp. 1247-1257, Jul. 2013.

[36] C. Eid, P. Codani, Y. Chen, Y. Perez, and R. Hakvoort, "Aggregation of demand side flexibility in a smart grid: A review for European market design," in Proc. 12th Int. Conf. Eur. Energy Market, May 20-22, 2015.

[37] A. Tascikaraoglu and B. M. Sanandaji, "Short-term residential electric load forecasting: A compressive spatio-temporal approach," Energy Buildings, vol. 111, pp. 380-392, Jan. 2016.

[38] N. G. Paterakis, O. Erdinc, and J. P. S. Catalão, "An overview of demand response: Key-elements and international experience," Renew. Sustain. Energy Rev., vol. 69, pp. 871-891, Mar. 2017.

[39] M. Baradar and M. R. Hesamzadeh, "AC power flow representation in conic format," IEEE Trans. Power Syst., vol. 30, no. 1, pp. 546-547, Jan. 2015.

[40] E. G. Kardakos, C. K. Simoglou, and A. G. Bakirtzis, "Optimal offering strategy of a virtual power plant: A stochastic bi-level approach," IEEE Trans. Smart Grid, vol. 7, no. 2, pp. 794-806, Mar. 2016.

[41] O. Ma et al., "Demand response for ancillary services," IEEE Trans. Smart Grid, vol. 4, no. 4, pp. 1988-1995, Dec. 2013.

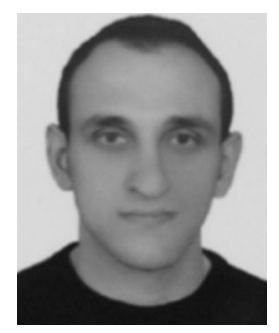

Akın Taşclkaraoğlu (S'12-M'14) received the B.Sc., M.Sc., and Ph.D. degrees from Yildiz Technical University, Istanbul, Turkey, in 2006, 2008, and 2013, respectively.

From 2013 to 2014, he was a Postdoctoral Scholar with the University of California, Berkeley. From 2012 to 2017, he was a Researcher with the Department of Electrical Engineering, Yildiz Technical University. Since 2017, he has been an Assistant Professor with the Department of Electrical and Electronics Engineering, Mugla Sitki Kocman University, Mugla, Turkey. His research interests include among others forecasting, renewable energy, power system operation, smart grid, and demand response. He is an Associate Editor for the IET Renewable Power Generation.

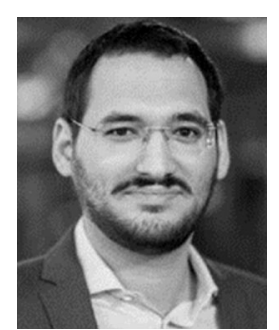

Nikolaos G. Paterakis (S'14-M'15) received the Dipl.Eng. degree from Aristotle University of Thessaloniki, Thessaloniki, Greece, in 2013, and the Ph.D. degree from the University of Beira Interior, Covilhã, Portugal, in 2015.

From October 2015 to March 2017, he was a Postdoctoral Fellow with the Department of Electrical Engineering, Eindhoven University of Technology, Eindhoven, The Netherlands, where he is currently an Assistant Professor. His research interests include power systems operation and planning, renewable energy integration, ancillary services, demand response, and smart grid applications. He is an Associate Editor for the IET Renewable Power Generation.

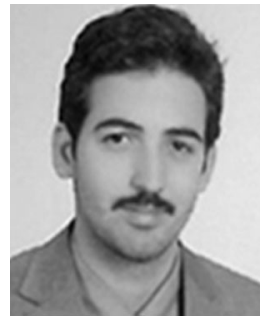

Ozan Erdinç (M'14-SM'16) received the B.Sc., M.Sc., and Ph.D. degrees from Yildiz Technical University (YTU), Istanbul, Turkey, in 2007, 2009, and 2012, respectively.

Until May 2013, he worked in the private sector in different positions including electrical installations, renewable energy investments, and as procurement expert. In June 2013, he became a Postdoctoral Fellow with the University of Beira Interior, Covilhã, Portugal, under the EU-FP7 funded Project "Smart and Sustainable Insular Electricity Grids Under Large-Scale Renewable Integration." Later, he joined the Department of Electrical Engineering, YTU, where in April 2016, he received the title of Doçent Dr. (Associate Prof. Dr.). He was also a Researcher with INESC-ID, Lisbon, Portugal. His research interests include hybrid renewable energy systems, electric vehicles, power system operation, and smart grid technologies. $\mathrm{He}$ is an Editor for the IEEE TRANSACTIONS ON SUSTAINABLE ENERGY and an Associate Editor for the IET Renewable Power Generation.

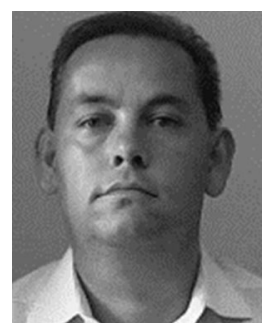

João P. S. Catalão (M'04-SM'12) received the M.Sc. degree from the Instituto Superior Técnico (IST), Lisbon, Portugal, in 2003, and the Ph.D. degree and Habilitation for Full Professor ("Agregação") from the University of Beira Interior (UBI), Covilha, Portugal, in 2007 and 2013, respectively.

$\mathrm{He}$ is currently a Professor with the Faculty of Engineering of the University of Porto (FEUP), Porto, Portugal, and a Researcher with INESC TEC, INESC-ID/IST-UL, and C-MAST/UBI. He was the Primary Coordinator of the EU-funded FP7 project SiNGULAR ("Smart and Sustainable Insular Electricity Grids Under LargeScale Renewable Integration"), a 5.2-million-euro project involving 11 industry partners. He has authored or coauthored more than 630 publications, including 230 journal papers (more than 65 IEEE transactions/Journal papers), 350 conference proceedings papers, two books, 34 book chapters, and 14 technical reports, with an h-index of 39, an i10-index of 146, and over 6015 citations (according to Google Scholar), having supervised more than 50 postdocs, and Ph.D. and M.Sc. students. He is the Editor of the books entitled Electric Power Systems: Advanced Forecasting Techniques and Optimal Generation Scheduling and Smart and Sustainable Power Systems: Operations, Planning and Economics of Insular Electricity Grids (Boca Raton, FL, USA: CRC Press, 2012 and 2015, respectively). His research interests include power system operations and planning, hydro and thermal scheduling, wind and price forecasting, distributed renewable generation, demand response and smart grids.

Prof. Catalão is an Editor for the IEEE TRANSACTIONS ON SMART GRID, the IEEE TRAnsactions on Power Systems, and a Subject Editor for the IET Renewable Power Generation. From 2011 to 2018 (seven years), he was an Editor for the IEEE TRANSACTIONS ON SUSTAINABLE ENERGY and an Associate Editor for the IET Renewable Power Generation. He was the Guest Editor-in-Chief for the Special Section on "Real-Time Demand Response" of the IEEE TRANSACTIONS ON SMART GRID, published in December 2012, and the Guest Editor-in-Chief for the Special Section on "Reserve and Flexibility for Handling Variability and Uncertainty of Renewable Generation" of the IEEE TRANSACTIONS ON SUSTAINABLE ENERGY, published in April 2016. Since May 2017, he is the Corresponding Guest Editor for the Special Section on "Industrial and Commercial Demand Response" of the IEEE TRANSACTIONS ON INDUSTRIAL INFORMATICS. Since March 2018, he is the Lead Guest Editor for the Special Issue on "Demand Side Management and Market Design for Renewable Energy Support and Integration" of the IET Renewable Power Generation. He was the recipient of the 2011 Scientific Merit Award UBI-FE/Santander Universities, the 2012 Scientific Award UTL/Santander Totta, the 2016 FEUP Diploma of Scientific Recognition, and the Best INESC-ID Researcher 2017 Award, in addition to an Honorable Mention in the 2017 Scientific Awards ULisboa/Santander Universities. Moreover, he has been a recipient of four Best Paper Awards at the IEEE conferences. 